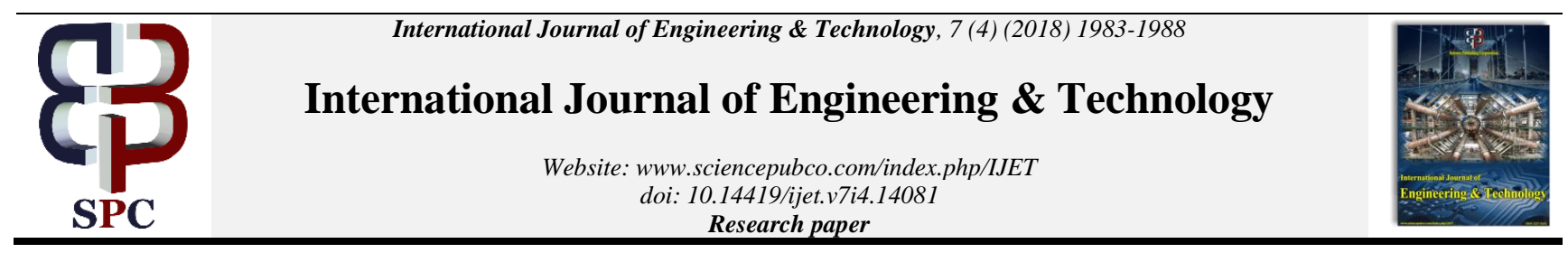

\title{
Insulating material based on shredded used tires and inexpensive polymers for different roofs
}

\author{
Fatma Zakaria ${ }^{1}$, M. A. Radwan ${ }^{1}$, M. A. Sadek ${ }^{1}$, Hany A. Elazab ${ }^{1 *}$ \\ ${ }^{1}$ Faculty of Engineering, Chemical Department, The British University in Egypt \\ *Corresponding author E-mail:Hany.Elazab@bue.edu.eg
}

\begin{abstract}
Thermal insulation is the ability of the material to prevent or reduce the heat transfer through the insulating material or between thermally contacted objectives. The increasing of the greenhouse effect leads to a continuous rising of the temperature especially in the summer, thus, there is a continuous research that aims to find more effective and environmental friendly insulation materials. Nowadays, a great number of proportions from polyurethane foam are produced every year in order to be used as an insulating material. Polyurethane foam shows an effective heat insulation results, but the price of the polyurethane is getting more expensive each day in Egypt due to the continuous rising of the hard currency as it is imported from abroad. This paper aims to prepare, design and develop effective heat insulation composite based on shredded used automobile tires. This was done by preparation different ratio composite from shredded used automobile tires and polyester along with polyurethane and shredded used automobile tires. These heat insulation tiles were characterized by the following testing, thermal insulation test, compression test, density measurement, abrasion test to measure the effect of adding the shredded used automobile tires to these polymers. It was found that, the composite of $66.7 \mathrm{wt} \%$ polyurethane foam and $33.3 \mathrm{wt} \%$ shredded automobile tires was the best choice to be used as it provides efficient thermal insulation of $\mathrm{K}$ value of $0.1663 \mathrm{~W} / \mathrm{m}$. ${ }^{\circ} \mathrm{C}$. It also has a low density of $0.0313 \mathrm{~kg} / \mathrm{l}$. Furthermore, the addition of shredded used automobile tires reduces the cost by $33 \%$. Furthermore, the compression strength of the polyurethane foam was increased by adding the shredded used automobile tires. Hence, using cheap materials such as shredded used tires, which considered as undesirable waste material, results in both producing a cheap national heat insulating roof tile with good mechanical, waterproofing and thermal insulating characteristics along with solving a serious environmental problem that occurs to get rid of the shredded waste automobile tires, as in some cases the tires are being burned resulting in air pollution and causing various diseases, which finally leading to more waste treatment management strategies. Finally, this heat insulation composite directly results in lowering the energy consumption required to cooling and heating systems inside the buildings.
\end{abstract}

Keywords: Insulating Materials; Shredded Used Tires; Polymers.

\section{Introduction}

In ancient eras, both mud plaster and straw were used as wall building insulators to reduce the heat transferred from the outsides. That solution was a moderate efficient solution during the whole season of autumn and spring. On the other hand, the mud plaster and straw did not insulate the heat efficiently during the winter and summer, as the temperature was very high in summer and very cold in winter inside the houses.[1]

Discovering of fiberglass in 1932 makes a breakthrough in the field of heat insulating materials as it shows a high insulating property in a way that it grew greatly and leaded the heat insulating materials that is used in building. Although fiberglass was more efficient and made homes more comfortable than the mud plaster and straw or any materials that were used in heat insulation before, it had some drawbacks. The major drawback of the fiberglass generally is the fine glass particles that is released to air which can be a reason of vital lung problems. Fiberglass also requires extremely gentle handling from the person while installing in order to prevent hand and body cuts. Fiberglass also requires a good ventilation system to ensure that the mold formation is highly avoided. Eventually, complex odd shapes of fiberglass cannot be achieved due to the difficulty of cutting of the fiberglass.[2]
Mineral wool is a combination of different types of several insulations. Those insulation can be fiberglass obtained from the recycled rubber, it can also be made from basalt which is called a rock wool insulation. Mineral wool can also be made from steel mills that come from the slag and called slag wool. In unites states, the major type used is the slag wool. The mineral wool insulation is purchased either as loose material or in batts. In extreme heat climates, mineral wool is not recommended to be used as it has no fire-retardant agents additives which leads to a poor fire resistance although it is not flammable material. When large areas are required to be effectively insulated in case of using conjunctions with other, a high amount of the fireresistant materials are needed. The thermal resistance value ( $\mathrm{R}$ value) of the mineral wool is ranging from [2].[8] to [3].[5].[3]

Due to the various drawbacks of using the fiberglass in heat insulation, cellulose was first used as a heat insulator in 1950s. It is a complex of old insulating materials including straw and some of the organic materials used for insulation that is mixed in a movable fill. Although the cellulose is not toxic and eliminated the drawbacks of the fiberglass, its thermal insulation efficiency was not high.[4]

Rigid insulators proved more insulation efficiency. This was discovered by making layers of polyester with different thicknesses and measures the heat insulation efficiency and it was proved that, polyester insulates more heat higher than the older materials used 
before for insulation. Although this idea gave a good satisfied heat insulation efficiency result in the exterior wall insulation, it was not applicable to precisely cut that rigid insulation for interior insulation.[5]

1970s was the turning point of the field of the building's heat insulation. Discovering of the poly foam was the breakthrough. Despite the discovery of the spray foams was in the 1940s, the using of the poly foams in the field of heat insulation was in 1970s. Spray foams are commonly used up till now in insulation. The two components of the poly foam are injected separately in a mixing machine and then at a nozzle in the end of the machine they are mixed and interacted forming the self-expanding foam. The chemical nature of the polyurethane makes it the ideal solution of the most challenging problems. The self-expanding property of the polyurethane facilitates the molding in any irregular shape besides enhancing both consumer as well as industrial products. Polyurethane is the product of the reaction between a polyol, which is a class of the alcohol that have more than two hydroxyl group, with polymeric isocyanate such as diisocyanate with suitable catalyst to enhance and accelerate the reaction along with some additives. As a result of the various types of both diisocyanate and polyols that can be reacted to produce polyurethane foam, there are a variety of the polyurethane foam types and each has different characteristics that can be used and selected according to the required specification of different applications.[2-6].

Although polyurethane shows a sufficient and acceptable insulation, the research did not stop for that result, new materials was added to polyurethane to enhance mechanical and thermal properties. For instance, in 2015 fly ash obtained from power plants that is produced from the burning of the coal and wood ash obtained from gasification process were added to flexible polyurethane foam. The study showed that, the composite of the fly and wood ash with the flexible polyurethane enhanced the mechanical properties. The addition of the ash also reduces the density beside a significant inhibition in the thermal degradation of the insulation material since the trapped gas inside the spherical particles of the ash affects the thermal insulation. Hence, the Results obtained from that research indicates that, both fly and wood ash can be considered as an efficient and successful modification to be added to the polyurethane foam as both of them was proven to be good thermal properties modifiers in polyurethane foams as fillers with a ratio from $5 \%$ up to a $15 \%$ of the total composite of ash and polyurethane foam. They enhanced the production economical aspects by decreasing the density of the material as well as lowering the total cost due to the low cost of the fillers. [5], [7], [17 - 19] It is well known that nanocomposites and nanoparticles have a great influence in the design of new materials that could be used in several applications.[8], [16], [20], [21-31] As a result of arousing the demand of heat insulation systems due to the increase of the greenhouse effect which leads to a continues rising of the temperature specially in the summer, there is a continuous research that aims to find more effective and environmental friendly insulation materials. Nowadays, a great number of proportions from polyurethane foam are produced every year in order to be used as an insulating material. The insulating layers of the foam are sprayed between the walls of buildings which eliminates or decrease the transfer of the heat from the outer environment to the building's interiors. Polyurethane foam shows an effective heat insulation results, but the price of the polyurethane is getting more and more expensive due to the continuous rising of the hard currency as it is imported from abroad. Therefore, using cheap materials such as shredded used tires which also considered as undesirable material will results in both producing a cheap national insulating tile with very good mechanical, waterproofing and thermal insulating characteristics along with solving a serious environmental problem that occurs to get rid of the shredded waste automobile tires, as in some cases the tires are being burned resulting in air pollution and causing various diseases, which finally leading to more waste treatment management strategies. Moreover, the more efficient the insulation is the less energy consumption is required to cooling and heating systems used inside the buildings.
The aim of this research paper is to prepare an efficient and cheap heat insulation composite from waste shredded used automobile tires and unsaturated polyester as inexpensive polymer and characterizes the mechanical properties along with flame resistance after adding a flame retardant agent which will end up with several benefits including excellent heat insulation that can be used in the building's roofs, usage of economical materials to produce the tile, managing the waste materials that are produced from other industries, providing both heat insulation and water proof using the same material which is recycled automobile tires. Taking into consideration the previous aims will result in an obvious reduction in the electricity bills as a result of the reduction in the usage of air conditioning in both winter and summer.

This will directly lead to a reduction in the greenhouse effect as air conditioners release the heat to air, an obvious decrease in the cost of investing of the buildings as the material of insulation becomes cheaper, a much greener environment by recycling the waste that leads to more waste management in the plant instead of burning and polluting the earth with the used tires and produce a heat insulating tile from it, reducing the pollution that is results from burning of the used tires to get rid of them.

\section{Experimental}

The chemicals were used as received without further treatment and they were purchased from Sigma Aldrich.

\subsection{Preparation of polyurethane foam}

In typical synthesis of polyurethane foam, the used mold is cleaned properly, then adequate amounts from the Vaseline is added in order to facilitate the process of removing the polyurethane from the mold. Then, $20 \mathrm{ml}$ di-isocyanate was added in a measuring cylinder, and then $20 \mathrm{ml}$ diol was added to another measuring cylinder. The content taken from both measuring cylinders was carefully poured instantaneously into the previously prepared mold while Keep mixing gently using a glass rod. Then, the polyurethane foam was left to expand and left to dry in the mold for 15 minutes. Finally, polyurethane foam is removed gently using spatula from the mold.

\subsection{Preparation of polyurethane foam and shredded automobile tires composite}

In the adopted procedure, the used mold is cleaned properly, and then adequate amounts of Vaseline were added to facilitate removing the polyurethane from the mold. The following procedure was implemented to prepare Polyurethane foam and Shredded Automobile Tire Composite (66.7 wt \% Polyurethane Foam and 33.3 wt \% Shredded Automobile Tires) in the same sequence respectively as $20 \mathrm{gm}$ of di-isocyanate, diol, and shredded automobile powder tires were added to three separate $250 \mathrm{ml}$ beaker. Then, both diisocyanate and diol were poured instantaneously into the mold. Once the foam starts to expand, the previously weighed 20 $\mathrm{gm}$ of the shredded automobile tires were added while maintaining mixing gently using a glass rod. Finally, the polyurethane foam is left to be expanded and dried in the mold for 15 minutes. Finally, polyurethane foam is removed gently using spatula from the mold.

\subsection{Preparation of polyester and shredded automobile tire composite}

In typical procedure, the used mold is cleaned properly, Clean the mold properly, then adequate amounts from the Vaseline is added in order to facilitate the process of removing the polyurethane from the mold. The following procedure was implemented to prepare Polyester and Shredded Automobile Tire Composite (30, 40, $50 \mathrm{wt} \%$ Polyurethane Foam and 70, 60, 50 wt \% Shredded Automobile Tires) in the same sequence respectively as $60,80,180 \mathrm{~g}$ polyester was added to $250 \mathrm{ml}$ beaker and then, $3 \mathrm{wt} \%(5.4 \mathrm{~g})$ 
activator was added to the polyester. Then, polyester and the activator are mixed together using a glass rod in order to obtain homogenous mixture. Then, another 140, 120, $180 \mathrm{~g}$ of shredded used automobile tires was added to another $250 \mathrm{ml}$ beaker and then, $3 \mathrm{wt} \%$ (5.4 g) initiator was added to the polyester while it is important to avoid mixing the activator with the initiator directly, otherwise an explosion may take place. Then, the mixtures were mixed thoroughly with glass rod to obtain homogenous mixture, and the composite mixture was added to the steel mold. The previously mentioned procedure could be repeated several times according to the mold size. Finally, the composite was left to be completely dried in the steel mold. The curing time takes about 3 days to be completely cured.
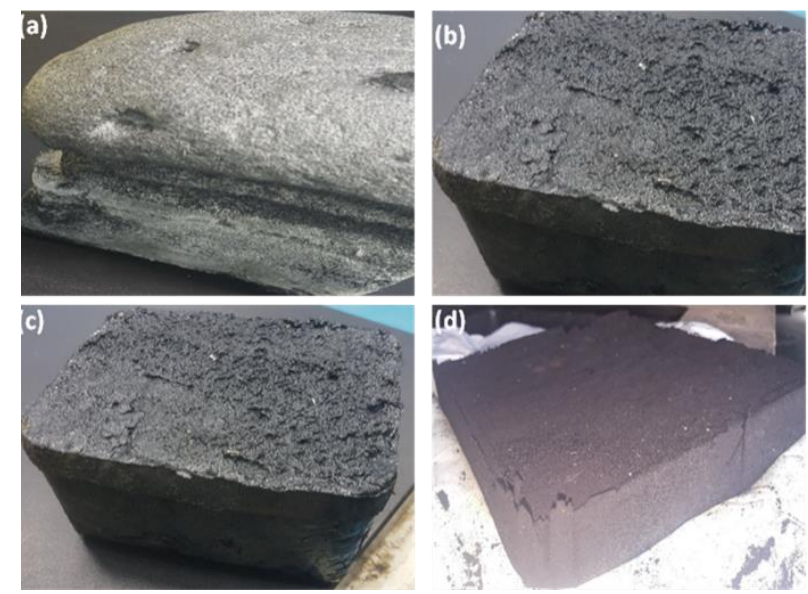

Fig. 1: A) Polyurethane and $33.3 \mathrm{Wt} \%$ Tires Composite, B) Composite of $50 \%$ Polyester 50\% Shredded Used Tires, (C) 60wt\% Shredded Used Tires and 40wt \% Polyester, and (D) 70wt $\%$ Shredded Used Tires and 30wt\% Polyester.

\subsection{Dimensions of the specimens}

\subsubsection{Thermal insulation and compression test specimen}

The specimen used for thermal insulation has $5 \mathrm{~cm}$ diameter for the polyester samples with tires and the pure polyester also with height of $0.5 \mathrm{~cm}$. The specimen used for the compression test has the previous dimension except for the height which is $2 \mathrm{~cm}$.
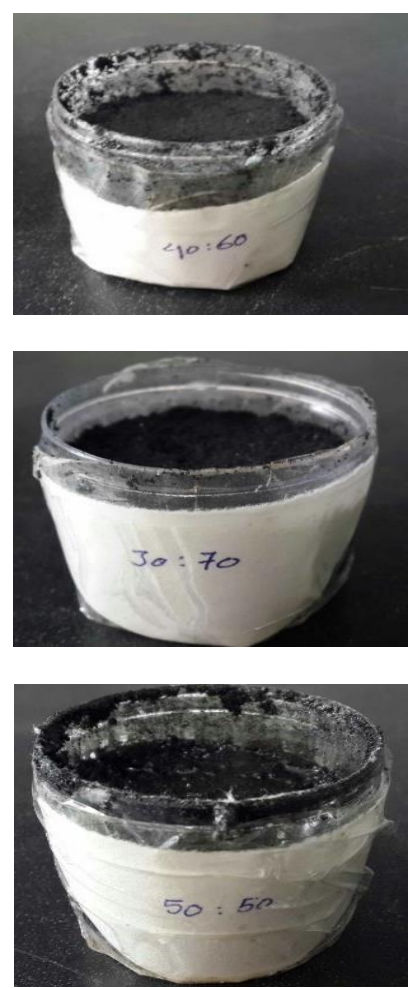

Fig. 2: Samples of Polyester and Shredded Used Automobile Tires Composites.

The specimen used for thermal insulation for the polyurethane foam samples with tires and the pure polyurethane foam has diameter of $5 \mathrm{~cm}$ with length of $0.5 \mathrm{~cm}$ while the samples of the compression test are a cubic specimen has a dimension of $5 \mathrm{~cm}$.
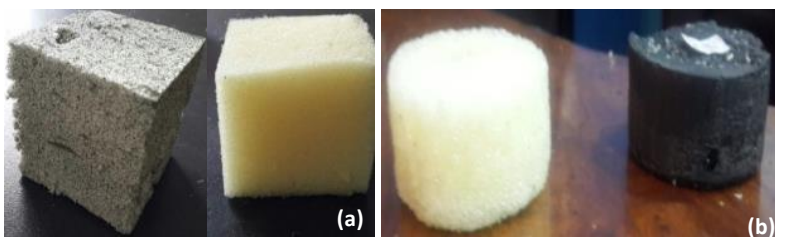

Fig. 3: A) Polyurethane Foam Specimens for Compression, B) Polyurethane Foam Thermal Insulation Specimen.

\subsubsection{Abrasion test specimen}

The specimen dimension is $5 \mathrm{~cm}$ height and has square cross section of one $\mathrm{cm}$ length and one $\mathrm{cm}$ wide.

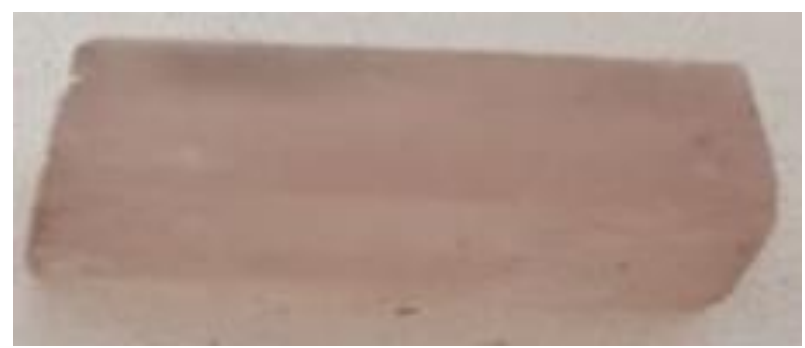

Fig. 4: Abrasion Test Specimen.

\subsubsection{Mechanical testing machine}

The tensile machine was used to measure the compression strength of the material and how it responds to the compression stresses. The compression machine has two jaws the first one is a fixed jaw and the second jaw is movable one that moves in a direction towards to the fixed jaw. The device is adjusted to compress the samples to half of its original length. The inputs to the machine test is the maximum load, the shape of the cross section of the samples (square, circular or tubal) and the dimensions of the specimen (length, height, diameter) according to the shape of the sample. The outputs are compression strength and the maximum elongation. The specimen of the polyurethane foam has square cross section while the samples of the polyester has circle cross section. The following two pictures showing the differences between some of the samples before and after compression test.

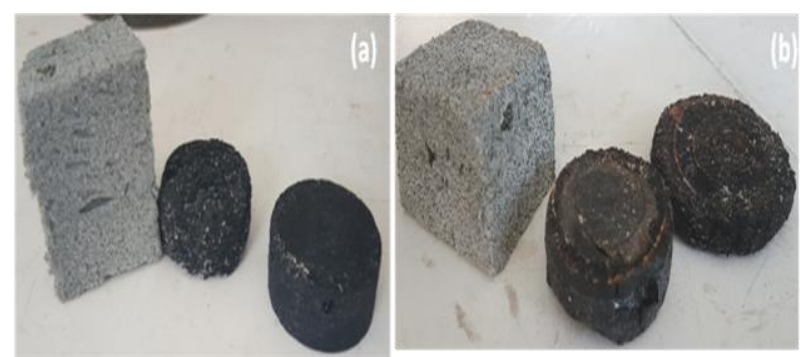

Fig. 5: Specimens A) before Compression, B) After Compression.

2.4.4. Thermal insulation measuring device 


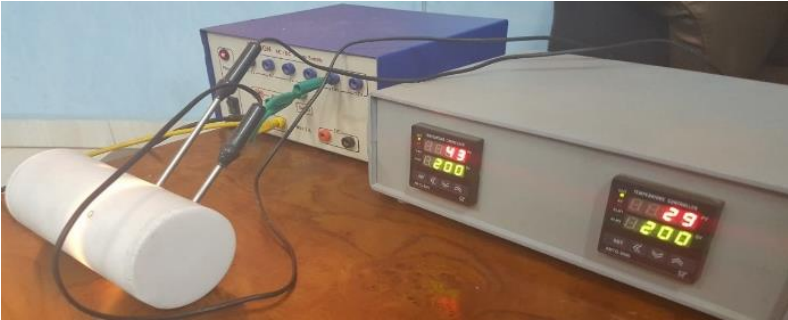

Fig. 6: Thermal Insulation Measuring Device.

The used thermal insulation measurement device composed of four main parts the first part is the power supply, the second part is the thermocouples that measures the temperature, the third part is the testing part where the specimen is applied and subjected to the heat, this art is insulated using a $0.5 \mathrm{~cm}$ Teflon to prevent heat losses to the surrounding. The fourth part is the digital thermometer reading. The supply power which generated the electrical heat with different voltages from 2 to 12 volt ( 2 volt, 4 volt, 6 volt, 8 volt, 10 volt and 12 volt) and different corresponding ampere leading to different amount of electrical energy. This circuit has a torch that has electrical energy equals to volt multiplied by the corresponding ampere. Assuming no loses all these amounts of energy is converted to heat energy using the torch. The torch was used instead of the heater to simulate the effect of the sun light that the insulation tile will be subjected to. The specimen must have circle cross section with dimension $50 \mathrm{~mm}$ for the diameter and a height of $0.5 \mathrm{~cm}$. hence, the thermal insulation factor $(\mathrm{K})$ is obtained by equalizing the two equations,

$\mathrm{Q}($ watt $)=\mathrm{V}($ volt $) * \mathrm{I}($ ampere $)=\frac{K A(T 2-T 1)}{X}$

where, $\mathrm{A}$ is the cross sectional area of the sample in $\mathrm{m}^{2}, \mathrm{~K}$ is the thermal conductivity in $\mathrm{W} / \mathrm{m} .{ }^{\circ} \mathrm{C}, \mathrm{T}_{2}$ is the temperature before the insulation in ${ }^{\circ} \mathrm{C}$ and the $\mathrm{T}_{1}$ is the temperature after the insulation in $\mathrm{C}$ and $\mathrm{x}$ is the thickness of the sample in $\mathrm{m}$.

\subsubsection{Abrasion test device}

The used abrasion test mechanism is based on applying load that pushes the tested material to the moving steel wheel that is moving with 50 revolutions per minutes that is connected with a motor through a gear. The test is measuring the amount loss from the material under these conditions. The specimen dimension is from three to ten $\mathrm{cm}$ height and has square cross section of one $\mathrm{cm}$ length and one $\mathrm{cm}$ wide. The weight of the specimen is measured by the balance before and after the test in order to get the percent loss of the material after different times. The load is changed from two to five-kilo grams.
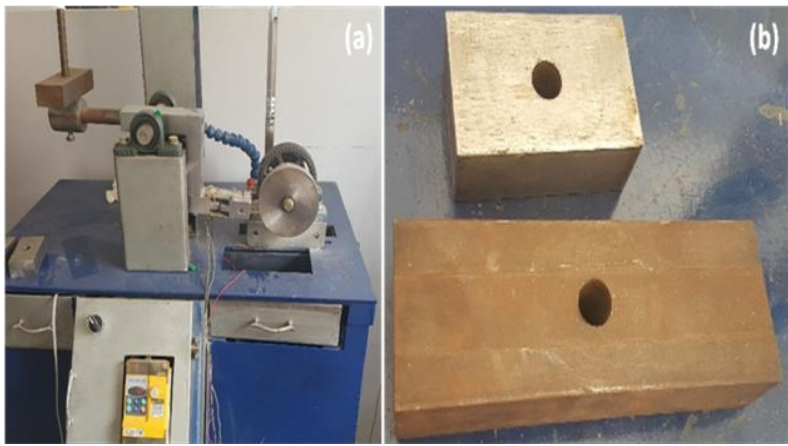

Fig. 7: A) Abrasion Machine, B) Abrasion Machine Loads.

\section{Results and discussion}

\subsection{Thermal insulation calculation ( $\mathrm{K}$ factor)}

Thermal insulation is important as it indicates the ability of the material to prevent or reduce the heat transfer through the insulat- ing material or between thermally contacted objectives. $\mathrm{K}$ factor that measures the ability of any materials to conduct the heat, thus, it is called the thermal conductivity factor. All the thermal conductive materials like metals have high value of thermal conductivity while the insulating materials have a thermal conductivity value that is lower than one. The lower the $\mathrm{K}$ value is, the more efficient the insulating material is.

From the experimental work done as shown in table 1, it was found that $\mathrm{K}$ factor of the pure polyester sample is 0.5927 $\mathrm{W} / \mathrm{m} .{ }^{\circ} \mathrm{C}$, while, $\mathrm{K}$ factor of the $50 \mathrm{wt} \%$ polyester $50 \mathrm{wt} \%$ shredded used automobile tires composite is $0.3951 \mathrm{~W} / \mathrm{m} .{ }^{\circ} \mathrm{C}$

It was also found that $\mathrm{K}$ factor of $40 \mathrm{wt} \%$ polyester $60 \mathrm{wt} \%$ shredded used automobile tires composite is $0.3793 \mathrm{~W} / \mathrm{m} .{ }^{\circ} \mathrm{C}$, while, $\mathrm{K}$ factor of $30 \mathrm{wt} \%$ polyester $70 \mathrm{wt} \%$ shredded used automobile tires composite is $0.3512 \mathrm{~W} / \mathrm{m} .{ }^{\circ} \mathrm{C}, \mathrm{K}$ factor of the pure polyurethane foam sample is $0.1859 \mathrm{~W} / \mathrm{m} .{ }^{\circ} \mathrm{C}$, and finally $\mathrm{K}$ factor of polyurethane foam and shredded automobile tires composite (66.7 wt \% polyurethane foam and $33.3 \mathrm{wt} \%$ shredded automobile tires) is $0.1663 \mathrm{~W} / \mathrm{m} .{ }^{\circ} \mathrm{C}$. It is clear that, the addition of the shredded used automobile tires either to the polyurethane foam or to the polyester reduces the $\mathrm{K}$ factor which indicates that, the thermal insulation is increased by adding the shredded used automobile tires. As the thermal insulation of the polyester is increased from [6] to [7] percentage by adding only $10 \mathrm{wt}$. percentage shredded used automobile tires. On the other hand, the addition of the shredded used automobile tires by [33] wt $\%$ to the polyurethane foam increases the thermal insulation by $10.54 \%$.

Table 1: Experimental Results Comparison before and after Insulation

\begin{tabular}{|c|c|c|c|}
\hline Sample & $\begin{array}{l}\text { Temperature } \\
\text { before insu- } \\
\text { lation }\left(\mathrm{T}_{2}\right)\end{array}$ & $\begin{array}{l}\text { Temperature } \\
\text { after insula- } \\
\text { tion }\left(\mathrm{T}_{1}\right)\end{array}$ & $\begin{array}{l}\mathrm{K}- \\
\text { Factor(W/m) }\end{array}$ \\
\hline Pure polyester & $66^{\circ} \mathrm{C}$ & $50^{\circ} \mathrm{C}$ & 0.592693008 \\
\hline $\begin{array}{l}50 \mathrm{wt} \% \text { polyester } 50 \mathrm{wt} \\
\% \text { shredded used auto- } \\
\text { mobile tires composite }\end{array}$ & $60^{\circ} \mathrm{C}$ & $36^{\circ} \mathrm{C}$ & 0.395128672 \\
\hline $\begin{array}{l}40 \mathrm{wt} \% \text { polyester } 60 \mathrm{wt} \\
\% \text { shredded used auto- } \\
\text { mobile tires composite }\end{array}$ & $60{ }^{\circ} \mathrm{C}$ & $35^{\circ} \mathrm{C}$ & 0.379323525 \\
\hline $\begin{array}{l}30 \mathrm{wt} \% \text { polyester } 70 \mathrm{wt} \\
\% \text { shredded used auto- } \\
\text { mobile tires composite }\end{array}$ & $61{ }^{\circ} \mathrm{C}$ & $34^{\circ} \mathrm{C}$ & 0.351225486 \\
\hline $\begin{array}{l}\text { Pure polyurethane foam } \\
\text { Polyurethane foam with }\end{array}$ & $85^{\circ} \mathrm{C}$ & $34{ }^{\circ} \mathrm{C}$ & 0.185942904 \\
\hline $\begin{array}{l}33 \text { wt } \% \text { shredded used } \\
\text { automobile tires com- } \\
\text { posite }\end{array}$ & $97^{\circ} \mathrm{C}$ & $40{ }^{\circ} \mathrm{C}$ & 0.166369967 \\
\hline
\end{tabular}

$\mathrm{Q}($ watt $)=\mathrm{V}($ volt $) * \mathrm{I}($ ampere $)=\frac{K A(T 2-T 1)}{X}$

Where, $\mathrm{A}$ is the cross sectional area of the sample in $\mathrm{m}^{2}, \mathrm{~K}$ is the thermal conductivity in $\mathrm{W} / \mathrm{m} .{ }^{\circ} \mathrm{C}, \mathrm{T}_{2}$ is the temperature before the insulation in ${ }^{\circ} \mathrm{C}$ and the $\mathrm{T}_{1}$ is the temperature after the insulation in ${ }^{\circ} \mathrm{C}$ and $\mathrm{x}$ is the thickness of the sample in $\mathrm{m}$.

The entire sample has, Diameter $=50 \mathrm{~mm}=0.05 \mathrm{~m}$, Length $=0.5$ $=\mathrm{cm}=0.005 \mathrm{~m}, \mathrm{I}=0.95 \mathrm{Amp}, \mathrm{V}=3.92$ Volt, $\mathrm{Q}=3.724$ Watt, A $=(\pi / 4) \mathrm{D}^{2}=0.001963495 \mathrm{~m}^{2}$

\subsection{Abrasion test result}

The samples of the polyester and shredded used automobile tires composite have to be coated with a polyester layer as it can be used as bricks and applied directly to the floors. Hence, the abrasion resistance was measured by using $2 \mathrm{~kg}$ load and $5 \mathrm{~kg}$ load for 3.5 under rate of $50 \mathrm{rpm}$ resulting in losses of $0.269 \%$ and 3.366 $\%$ respectively. From literature the losses of boly urethane foam under these conditions are 20 and $30 \%$ respectively. Therefore, it is applied as a layer under a concrete layer in order to protect the polyurethane foam from abrasion. 


\subsection{Compression test results}

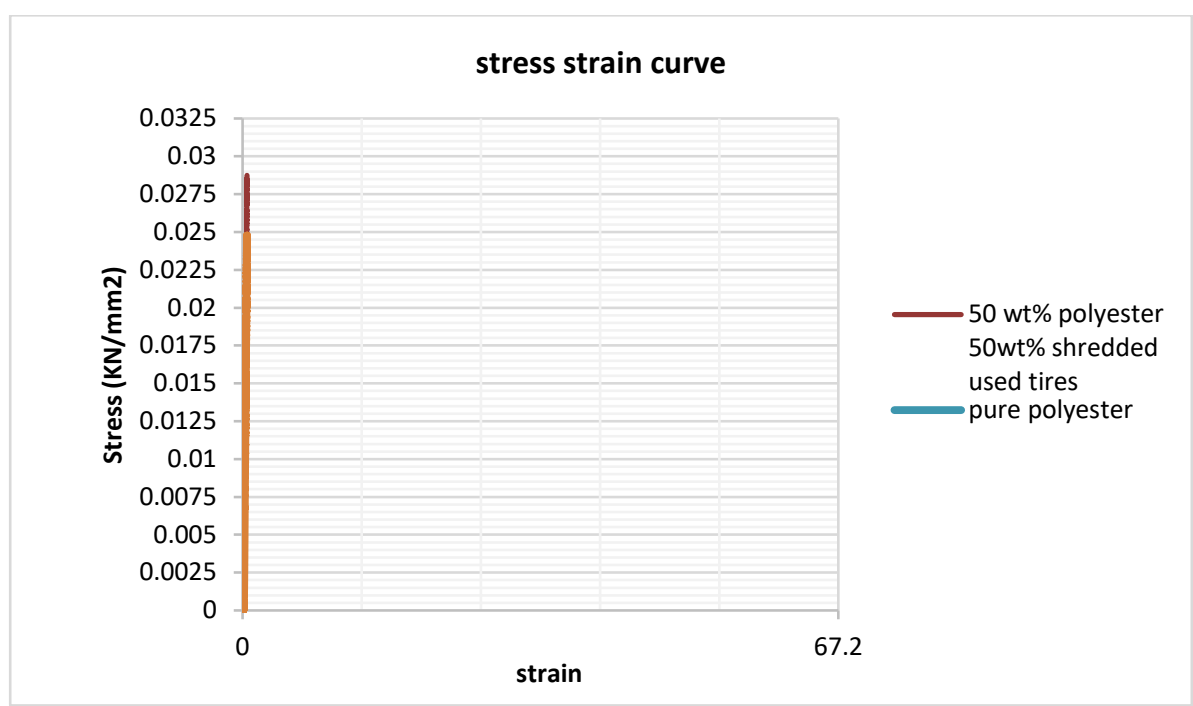

Fig. 8: Stress Strain Curve For Polyester and Used Automobile Tires Composite.

From the experimental results, it was found that the addition of the shredded used automobile tires increases the rubbery properties of the materials. In order to compare between the samples, the tensile machine was adjusted to do the compression test till the samples are compressed to half of its original length. The sample of the 50 wt $\%$ polyester $50 \mathrm{wt} \%$ shredded used automobile tires composite fails before it compresses to $10 \%$ from its original length.

The sample of $40 \mathrm{wt} \%$ polyester $60 \mathrm{wt} \%$ shredded used automobile tires composite and the sample of $30 \mathrm{wt} \%$ polyester $70 \mathrm{wt} \%$ shredded used automobile tires composite did not fail due to addion of rubber in higher amounts. The compression at deformation of $50 \%$ from the original length for the sample of $40 \mathrm{wt} \%$ polyester 60 wt $\%$ shredded used automobile tires composite is 0.028 $\mathrm{kN} / \mathrm{mm}^{2}$ while the compression at deformation of $50 \%$ from the original length for the sample of $30 \mathrm{wt} \%$ polyester $70 \mathrm{wt} \%$ shredded used automobile tires composite is $0.025 \mathrm{kN} / \mathrm{mm}^{2}$. Consequently, the addition of the shredded used automobile tires increases mechanical properties of the polyurethane foam. By addition of $33 \mathrm{wt} \%$ of shredded used automobile tires, the compression stress that is required to compress the sample to half of its original length was increased from $0.00006 \mathrm{kN} / \mathrm{mm}^{2}$ which is the compression strength of the pure sample of the polyurethane foam till it reached $0.000175 \mathrm{kN} / \mathrm{mm}^{2}$ by adding the shredded used tires. The compression strength of the polyurethane foam was increased by adding the shredded used automobile tires as it filled the voids of the polyurethane foam.

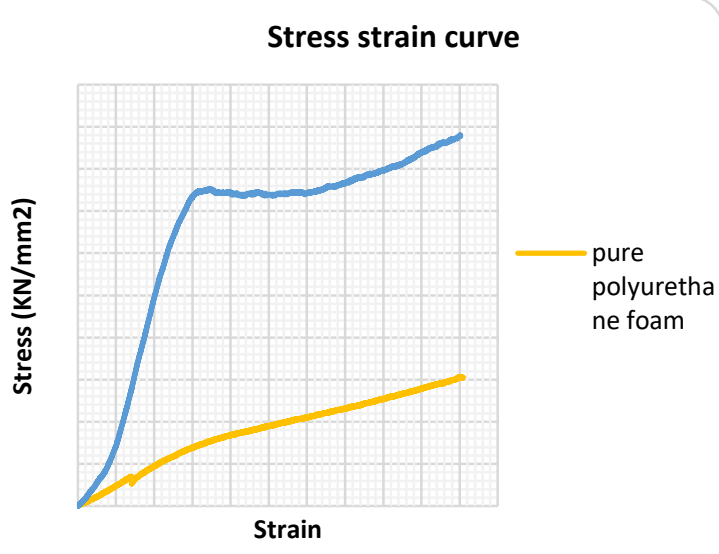

Fig. 9: Stress Strain Curve for Pure Polyurethane Foam and Foam with Shredded Used Tires Composite.

\section{Conclusions}

In conclusion, polyurethane foam is used as efficient heat insulation. However, the manufacture of the polyurethane foam may not cause severe environmental problems, polyurethane foam does not make any contribution to have a greener earth. According to the information mentioned and stated in this report, using the shredded used automobile tires old tires and making use of it can make a main environmental benefit because accumulating of these bulk used tires makes a lot of problems while getting rid of it making high pollution rates. Thus, shredded used automobile tires were added to both polyester and polyurethane foam. The composites prepared and tested was $50 \mathrm{wt} \%$ polyester $50 \mathrm{wt} \%$ shredded used automobile tires composite, $40 \mathrm{wt} \%$ polyester $60 \mathrm{wt} \%$ shredded used automobile tires composite, $30 \mathrm{wt} \%$ polyester $70 \mathrm{wt} \%$ shredded used automobile tires composite and finally, $66.7 \mathrm{wt} \%$ polyurethane foam and $33.3 \mathrm{wt} \%$ shredded automobile tires. Thermal insulation test, compression test, density measurement, abrasion test was done to all these composites and measure the effect of adding the shredded used automobile tires to these polymers. The composite of $66.7 \mathrm{wt} \%$ polyurethane foam and $33.3 \mathrm{wt}$ $\%$ shredded automobile tires was the best choice to be used as it provides efficient thermal insulation of $\mathrm{K}$ value of $0.1663 \mathrm{~W} / \mathrm{m} .{ }^{\circ} \mathrm{C}$. It also has a low density of $0.0313 \mathrm{~kg} / \mathrm{l}$. Moreover, the addition of shredded used automobile tires reduces the cost by $33 \%$. Furthermore, the compression strength of the polyurethane foam was increased by adding the shredded used automobile tires as it filled the voids of the polyurethane foam. On the other hand, shredded used tires and polyurethane foam are water proofing materials but the automobile tires is highly flammable material therefore, flame retardant reagent has to be added to the polyurethane and the shredded used automobile composite as safety precaution of the building. Finally, the project fulfills its aim by providing environmental economic heat insulation material based on shredded used automobile tires that has good insulation effect beside acceptable mechanical properties.

\section{References}

[1] Papadopoulos, A. M., State of the art in thermal insulation materials and aims for future developments. Energy and Buildings, 2005. 37 (1): p. 77-86. https://doi.org/10.1016/j.enbuild.2004.05.006.

[2] Tang, Y., et al., Industrial polymers classification using laserinduced breakdown spectroscopy combined with self-organizing maps and K-means algorithm. Optik. 165: p. 179-185. 
[3] Piszczyk, A. u., et al., Polyurethane/ground tire rubber composite foams based on polyglycerol: Processing, mechanical and thermal properties. Journal of Reinforced Plastics and Composites. 34(9): $p$. 708-717.

[4] Dowson, M., et al., Predicted and in situ performance of a solar air collector incorporating a translucent granular aerogel cover. Energy and Buildings.49: p. 173-187.

[5] Naskar, A.K., A.K. Mukherjee, and R. Mukhopadhyay, Studies on tyre cords: degradation of polyester due to fatigue. Polymer Degradation and Stability, 2004. 83(1): p. 173-180. https://doi.org/10.1016/S0141-3910(03)00260-X.

[6] Parres, F., J.E. Crespo-Amor $\tilde{A}^{3}$ s, and A. Nadal-Gisbert, Mechanica properties analysis of plaster reinforced with fiber and microfiber obtained from shredded tires. Construction and Building Materials, 2009.23(10): p. $3182-3188$ https://doi.org/10.1016/j.conbuildmat.2009.06.040.

[7] Lauri, J. and R. Scapellato, Topics in Graph Automorphisms and Reconstruction. London Mathematical Society Lecture Note Series, Cambridge: Cambridge University Press.

[8] Elazab, H., et al., Microwave-assisted synthesis of Pd nanoparticles supported on $\mathrm{FeO}, \mathrm{CoO}$, and $\mathrm{Ni}(\mathrm{OH})$ nanoplates and catalysis application for CO oxidation. Journal of Nanoparticle Research, 2014. 16(7): p. 1-11.

[9] Elazab, H., et al., The Effect of Graphene on Catalytic Performance of Palladium Nanoparticles Decorated with $\mathrm{FeO}, \mathrm{CoO}$, and $\mathrm{Ni}$ $(\mathrm{OH})$ : Potential Efficient Catalysts Used for Suzuki CrossCoupling. Catalysis Letters. 147(6): p. 1510-1522.

[10] Elazab, H.A., et al., The continuous synthesis of Pd supported on Fe3O4 nanoparticles: A highly effective and magnetic catalyst for CO oxidation. Green Processing and Synthesis. 6(4): p. 413-424.

[11] Elazab, H.A., et al., Highly efficient and magnetically recyclable graphene-supported $\mathrm{Pd} / \mathrm{Fe} 3 \mathrm{O} 4$ nanoparticle catalysts for Suzuki and Heck cross-coupling reactions. Applied Catalysis A: General, 2015. 491 p. 58-69.

[12] Mankarious, R.A., et al., Bulletproof vests/shields prepared from composite material based on strong polyamide fibers and epoxy resin. Journal of Engineering and Applied Sciences. 12(10): p. 2697-2701.

[13] Mohsen, W., M.A. Sadek, and H.A. Elazab, Green synthesis of copper oxide nanoparticles in aqueous medium as a potential efficient catalyst for catalysis applications. International Journal of Applied Engineering Research.12 (24): p. 14927-14930.

[14] Mostafa, A.R., H.A.-S. Omar, and A.E. Hany, Preparation of Hydrogel Based on Acryl Amide and Investigation of Different Factors Affecting Rate and Amount of Absorbed Water. Agricultural Sciences. Vol.08No.02: p. 11.

[15] Radwan, M.A., et al., Mechanical characteristics for different composite materials based on commercial epoxy resins and different fillers. Journal of Engineering and Applied Sciences. 12(5): p. 1179-1185.

[16] Kobayashi, T., Kanematsu, H., Hashimoto, R., Morisato, K., Ohashi, N., Yamasaki, H., \& Takamiya, S. (2013). Study on Environment and Energy Using Belonging Materials. International Journal of Sustainable Development \& World Policy, 2(4), 50.

[17] Chan, Wu-Chung, and Hong-Siou Guo. "Preparation of a Poly (Vinylalcohol) (PVA)/Peat/Organoclay/Kno3 Composite Bead as Biofilter Material for Biofiltration of Volatile Organic Compounds." The International Journal of Biotechnology 3, no. 2 (2014): 24-31.

[18] Nwufo, B. T., Priscila, A. U., \& Onche, E. U. (2014). Production of Cost-Effective Adsorbents from Native Materials. International Journal of Chemistry and Materials Research, 2(4), 30-35.

[19] El-Agez, T. M., El-Ghamri, H. S., Abdel-Latif, M. S., Taya, S. A., \& Alkanoo, A. A. (2014). Thermoelectricity Based on Cuo as a Semiconducting Material. International Journal of Chemistry and Materials Research, 2(12), 166-173.

[20] Murugadoss, K., \& Pasupathi, G. (2015). Hardness Studies on Solution Grown Lithium Potassium Sulphate Single Crystals-An Inorganic Nonlinear Optical Material. International Journal of Chemistry and Materials Research, 3(1), 11-16.

[21] B. Ashraf, M. A. Radwan, M. A. Sadek, H. A. Elazab International Journal of Engineering and Technology(UAE), 7, 1295-1298.

[22] H. A. Elazab Biointerface Research in Applied Chemistry, 8, 3314 3318 .

[23] H. A. Elazab Biointerface Research in Applied Chemistry, 8, 3278 3281 .

[24] H. A. Elazab, M. A. Radwan, T. T. El-Idreesy International Journal of Nanoscience, 2018.

[25] H. A. Elazab, M. A. Sadek, T. T. El-Idreesy Adsorption Science \& Technology, 36, 1352-1365.
[26] N. S. Samir, M. A. Radwan, M. A. Sadek, H. A. Elazab International Journal of Engineering and Technology(UAE), 7, 1290-1294.

[27] Fatma Zakaria, M. A. Radwan, M. A. Sadek, H. A. Elazab International Journal of Engineering and Technology(UAE), 7, 2018.

[28] Reem Nasser, M. A. Radwan, M. A. Sadek, H. A. Elazab International Journal of Engineering and Technology(UAE), 7, 2018.

[29] Mostafa Ghobashy, Mamdouh Gadallah, Tamer T. El-Idreesy, M. A. Sadek, H. A. Elazab International Journal of Engineering and Technology(UAE), 7, 2018.

[30] H. A. Elazab, M. A. Sadek, Biointerface Research in Applied Chemistry, 8, 2018.

[31] Hany A. Elazab, The Canadian Journal of Chemical Engineering, volume 96 , issue 10,2018 